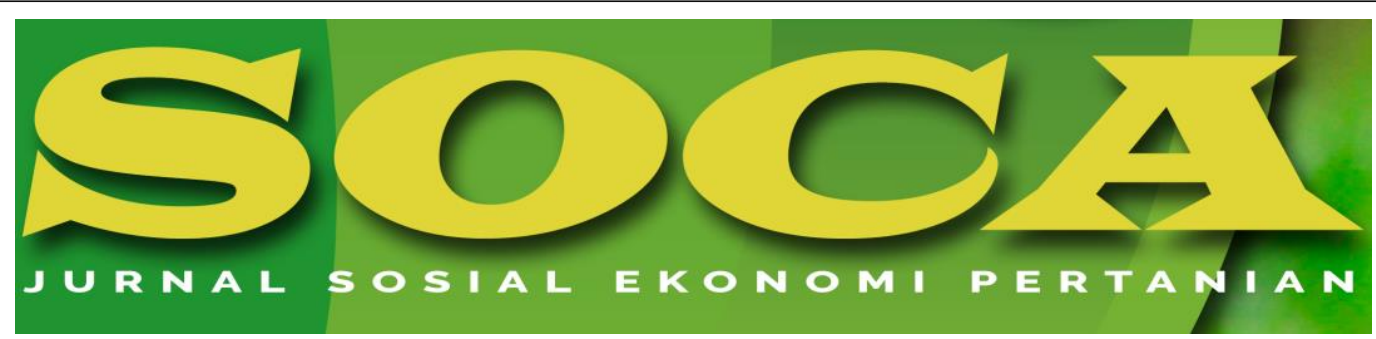

https://ojs.unud.ac.id/index.php/soca

\title{
The KoBoCollect for Research Data Collection and Management (An experience in Researching the Socio- Economic Impact of Blood Disease in Banana)
}

\author{
I Wayan Nampa ${ }^{1}$, I Wayan Mudita ${ }^{1}$, Norman Patrick Lucky Bire Riwu Kaho ${ }^{1}$, Sri \\ Widinugraheni ${ }^{1}$, Remi Lasarus Natonis ${ }^{2}$ \\ ${ }^{1}$ Faculty of Agriculture, Nusa Cendana University \\ 2 Department of Agriculture and Food Security of East Nusa Tenggara Province \\ Email: wayannampa@staf.undana.ac.id \\ Mobile: 08113828669
}

Submitted: January 27th, 2020; Revised: March 19th, 2020; Accepted: May 7th, 2020

\begin{tabular}{ll}
\hline Keywords: & Abstract \\
Banana; & In the research field, smartphone began to be used for field data \\
kobocollect; & collection. One application that was used was KoBoCollect. This \\
kobotoolbox; & article shared the experience of using KoBoCollect in research \\
blood disease in & on the socio-economic impact of blood diseases on banana in \\
banana; socio- & Sumba Island. The research was conducted by interviewing 64 \\
economic impact & banana farmers that spread proportionally in four regencies in \\
& Sumba Island. The use of KoBoCollect/toolbox made it easy to \\
& collect, save and manage research data. KoBoCollect/toolbox \\
& provided the advantages of conducting paperless research, able \\
& to record data in complex formats such as numeric data, \\
& descriptive data, photos, videos, sounds, coordinates and other \\
& data, dynamically making forms changes when conducting \\
& research, and displaying interactive applications. KoBoCollect \\
& can be run off-line, made it possible to collect field data in \\
& remote locations and no internet network. The research data \\
& was transmitted online so that the data tabulation process was \\
& automatic. Simple data analysis such as median values, mode, \\
graphs and distribution maps of data collection were provided \\
in KoBotoolbox. With KoBoCollect/toolbox, researchers quickly \\
find out the results of the research, as in this research it was \\
known that blood disease had an impact on the decrease in the \\
banana population revealed by 81.54\% of farmers.
\end{tabular}


How to Cite (APA 6th Style):

Nampa, I. W., Mudita, I. W., \& Kaho, N. P. L. B. R. (2020). The KoBoCollect for Research Data Collection and Management (An experience in Researching the Socio-Economic Impact of Blood Disease in Banana ). SOCA: Jurnal Sosial Ekonomi Pertanian, 14(3), 546-557.

https://doi.org/https://doi.org/10.24843/SOCA.2020.v14.i03.p15

\section{INTRODUCTION}

The development of communication and information technology gave influence in various fields of life. Information and communication technology, which had become an icon of the fourth industrial revolution, was able to disrupt various technologies that previously existed. According to Prasetyo and Trisanti (2018), the industrial revolution not only disrupted the technology sector, but also other fields, such as law, economics, social and research. The technological developments resulted in disturbances, so we must continue to innovate to keep abreast of developments, so that we were not only able to meet current needs but also be able to compete in the future.

In the field of research, technology transition (distruption) was rapidly occurring. Various research instruments continued to be developed to support researchers in doing their job. One of them was the use of information technology. Information technology had not only developed in the field of technology research, but also in other fields such as social, economic and cultural. Prasetyo and Trisanti (2018) said that the phenomenon of distortion extended to the fields of education, government, culture, politics, and law. The development of research instruments by utilizing information and communication technology was expected to accelerate and facilitate the implementation of research.

In social research based on the field surveys, the questionnaire was one of the key instruments in data collection. Dauenhauer et al. (2019) and Tayal et al. (2015) revealed that surveys using paper questionnaires had challenges including in costing, having to physically distribute, handle and return survey results, and had a high potential for error. This required a long process to get results, because it must go through a tabulation process from the questionnaire to data, then statistics can only be analyzed for a long time and it was quite difficult to do. In addition, the paperbased questionnaire enabled survey officers to provide qualitative answers to the quantitative questions section so it produced unexpected data. Meanwhile, the only advantage of using paper-based questionnaire was no need to perform training about how to use of survey equipment.

The research on the social impact of blood diseases on banana was performed outside the residence and office of the researchers (home base). The research was conducted in Sumba Island, while the home base of researchers was in Kupang City. Travel by airplane or ship was needed to reach the research location. Travel time by airplane can be taken approximately one hour, but if using a ship it took more than 24 hours. If the researcher used a paper-based questionnaire, he must carry around 900 sheets of questionnaire papers. In addition, if the data collection required repetition due to an error, a backup questionnaire was needed, and it took time to send data from the research location to the researcher's home base. Therefore, 
research instruments that needed were instruments that easy to use, fast, and concise.

To answer these needs, researchers found KoBoCollect/Toolbox as a digital questionnaire instrument that based on websites and applications on the Android system. KoBoCollect/Toolbox was an open source field data collection instrument that developed in collaboration with Harvard Humanitarian Initiative, Brigham and Women's Hospital and Kweyo as explained on KoBo's website (www.koboToolbox.org). KoBoCollect/Toolbox was developed to support field data retrieval which was able to summarize some work and equipment such as questionnaire paper, GPS, Camera, voice recording devices, and other equipment into one instrument that can be tethered to a smartphone. In addition, this instrument also simplified research work because the data tabulation process was performed automatically and the provided data format can be adjusted to the needs of research analysis. Deniau et al. (2017) revealed that the use of KoBoCollect was more time efficient and also research cost, it can even record coordinate data accurately. However, based on the author's search, no Indonesian-language articles had been found that shared the experience of using KoBoCollect/Toolbox in social research.

How was the application of KoBoCollect/Toolbox as a research instrument to replace several instruments at once? This article was written to share the experience of using KoBoCollect/Toolbox in field data collection on the research of socioeconomic impacts and the spread of blood diseases in banana in Sumba Island, considering that there had not been many articles especially Indonesian language articles that discussed the use of this instrument. This article will discuss how the experience of using KoBoCollect/Toolbox as a digital data collection instrument, the ease and challenges that encountered during its usage.

\section{RESEARCH METHODS}

This research was conducted in four Regencies in Sumba Island, East Nusa Tenggara Province. The research performed in August to November 2019. The selection of Sumba Island as a research location was because Sumba was a new area that was experiencing the spread of blood disease in banana. According to Wardlaw 1972 (in Mairawita et al., 2012) Blood disease in banana was caused by the bacterium Ralstonia syzigii which was first reported in 1907 which occurred on Selayar Island, South Sulawesi Province. Since it was first reported, blood disease in banana spread to various regions in Indonesia. Sumba Island was one of the areas that reported blood disease in banana starting in the 2010s. Blood disease in banana caused severe damage to banana plants on Sumba Island in 2012-2016.

\section{KoBo Collect/Toolbox as the Research Instrument}

The data collection in this research used KoBoCollect/Toolbox as a data collection instrument. The utilization/use of KoBoCollect/Tollsbox in this research was for data collection instruments in the form of questionnaires/forms that can be filled quickly in a smartphone. Chronologically, the research was performed in several stages which were stages of compiling a research questionnaire, compiling a digital questionnaire on the KoBoToolbox server, deploying forms/questionnaires, downloading forms/questionnaires from smartphones, recruiting enumerators (field 
officers), conducting training in the use of instruments to enumerators, collecting data, sending data (uploading data), and downloading data and data presentation. The illustration of the stages of preparing the questionnaire to downloading and presenting data using KoBoCollect/Toolbox was presented in Picture 1.

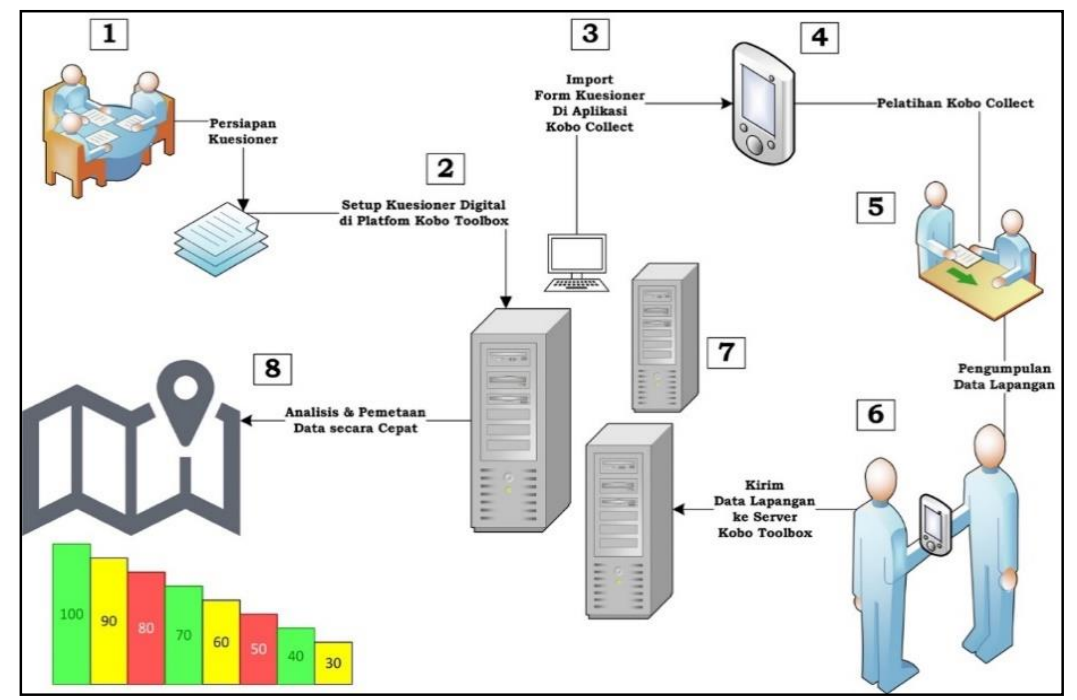

Picture 1. Workflow of Using KoBoCollect/Toolbox Instrument (Riwu Kaho, 2019)

Picture information:

1 = Preparing questionnaires

2 = Set-up digital questionnaires on the KoBoToolbox platform

$3=$ Importing questionnaire forms in the KoBoCollect application

$4=$ KoboCollect training

$5 \quad=$ Field Data Collection

6 = Sending field data to KoboToolbox server

$7 \quad$ KoboToolbox server

8 = Quick analysis and mapping data

As illustrated in Picture 1, KoboCollect/Toolbox became an important instrument in conducting research data management, from recording data to presenting data. Research on the socio-economic impact of blood disease on banana in Sumba Island used two forms, physical data forms and social economic impact forms. Each form was used to record data in four regencies in Sumba Island. The determination of research respondents used a systematic stratified sampling method, which was by taking two sub-districts in each regency. Each sub-district was chosen two villages which were banana centers. The total number of research respondents was 64 respondents (Table 1), with spatial distribution as presented in Picture 3.

Table 1. Number and Distribution of Research Respondents

\begin{tabular}{cccc}
\hline No & Regency & $\begin{array}{c}\text { Number of } \\
\text { Respondents }\end{array}$ & (\%) \\
\hline 1 & East Sumba & 18 & 27,69 \\
2 & $\begin{array}{c}\text { Southwest } \\
\text { Sumba }\end{array}$ & 17 & 26,15 \\
\hline
\end{tabular}




\begin{tabular}{cccc}
\hline 3 & Central Sumba & 15 & 23,08 \\
4 & West Sumba & 14 & 21,54 \\
& Total & 64 & 100,00
\end{tabular}

Source: questionnaire distribution results (2019)

\section{Data Collection Equipment}

KoBoCollect/Toolbox was a collection of field data that was transmitted electronically to a server that was managed through a website. As explained earlier, for preparing questionnaires/forms, managing data, downloading and presenting data was done on the KoBoToolbox website via the https://www.kobotoolbox.org website. Therefore, researchers who want to use KoBoCollect/Toolbox in field data collection must first prepare a questionnaire on the KoBotoolbox. In order to compile a questionnaire, you must first create an account on the KoBotoolbox website with the website address as mentioned above. The types of questions/data that can be recorded on the form/questionnaire as presented in Picture 2. Therefore, researchers need a computer/laptop that can be connected to the internet to prepare forms/questionnaires on the KoBoToolbox server, share forms, download data, and make presentations data. If compiling and managing data using KoBoToolbox, the KoBoCollect application can be installed to retrieve field data that can be installed on a smartphone with an Android operating system. Through KoBoCollect, forms that have been compiled on the KoBoToolbox website can be downloaded by first synchronizing/matching user names and passwords between users on the website and the KoBoCollect application on the smartphone.

KoBoCollect was an application on a smartphone that can be downloaded via the google play store. Therefore, the main equipment used in data collection was a smartphone with an Android operating system. Basic facilities that must be available on a smartphone for field data collection including: photo and video cameras, GPS, and voice recorder. With this facility, each smartphone can be used to collect data. However, smartphone quality will also affect data quality, especially image data (photos and videos). The better the quality of the smartphone, of course it will produce better data. In addition, the smartphone that used must have enough storage space (memory) during data collection in the field.

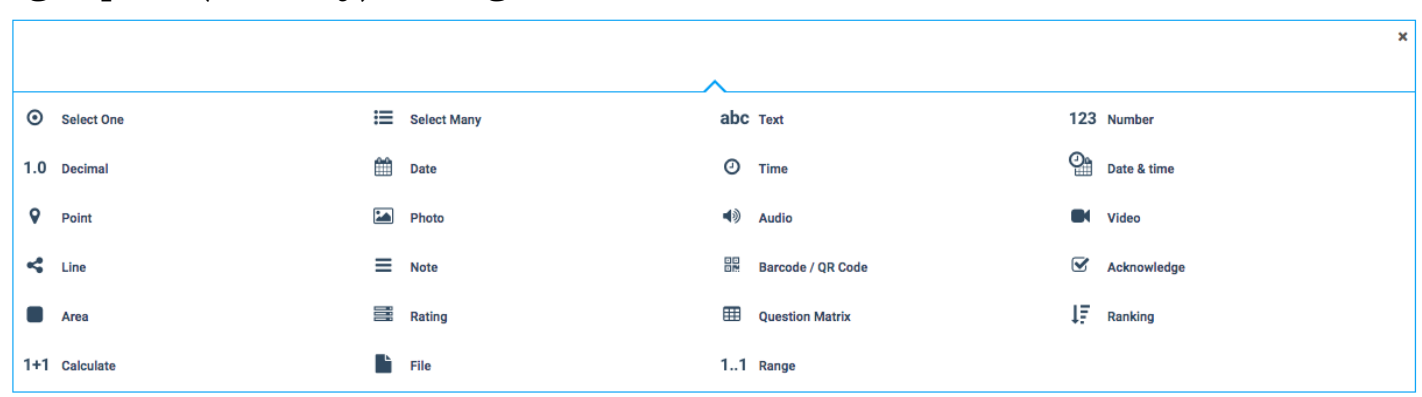

Picture 2. Type of Questions/Data which can be Recorded in Compiling Forms/Questionnaire on KoBoToolbox (Source: capture KoBoToolbox, 2020)

\section{RESULTS AND DISCUSSION Work with KoBoCollect}

The development of smartphone technology provided an opportunity to do data collection faster and at lower costs. Le Bel and Stansfield. (2016) used the 
KoBoCollect android application on smartphones to do geographic data recording, in building an early warning system, conflicts between humans and wildlife that occur in South Africa. After adopting KoBoCollect on smartphones, an early human-wildlife conflict (HWC) warning system can be used at a low cost, improving the global management and conservation of the leading species that involved in HWC. The use of KoBoCollect in research of the socio-economic impact of blood disease on banana also made data collection/recording during the survey more concise, and reduced the cost of doubling the questionnaire paper, cutting the cost of data tabulation, and also the leasing of tools such as GPS for determining the location of coordinates. In addition, because data retrieval was done digitally, it can minimize recording errors, especially in coordinate data. Coordinate data was sensitive data in recording errors. If there was an error in a single digit, it will cause a change of location which was quite deviating from the actual location. The experience of collecting data on the socio-economic impact of blood disease on banana in 2017 at the research location showed that there were some minor mistakes that caused the principle error because the location coordinates did not match the location of the data collection. Even after the analysis was done, the location recorded was in the water area, so the data must be checked again. The results of coordinate data retrieval using KoBoCollect had a slightly lower level of accuracy (depending on the device) compared to the use of GPS in general, but because coordinate data retrieval was directly recorded on KoBoCollect, so recording errors can be minimized. Picture 3 was the result of coordinate data about the distribution of data collection on the socio-economic impact of blood disease on banana in Sumba Island.

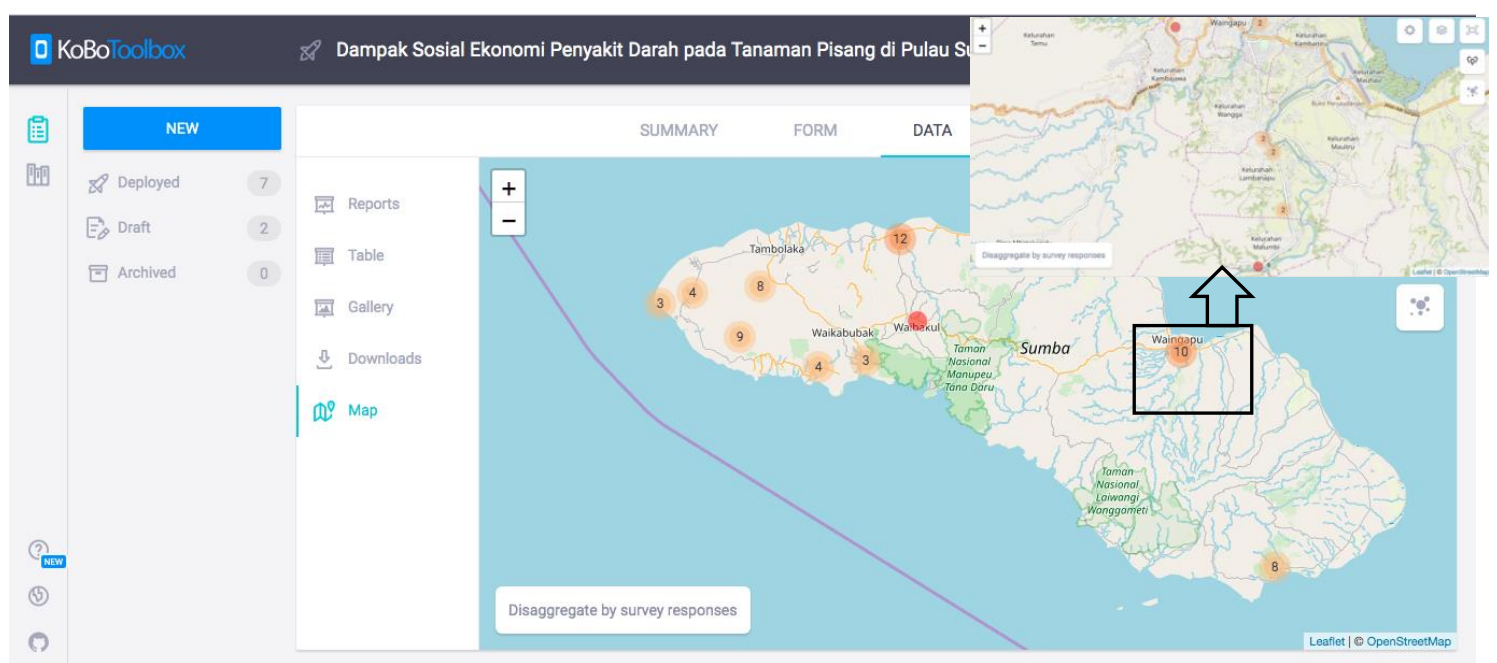

Picture 3. Distribution and number of respondents that were interviewed in collecting data of Social Impact of Blood Desease on Banan in Sumba Island (research results, 2019)

The process of collecting data while at the research location became more concise and simple. Research enumerators can focus on one data collection instrument, which was smartphones. In addition, the enumerator will focus on each question item that appeared on the smartphone screen, so that the enumerator was not interrupted by a list of other questions that were not being asked. In KoBoCollect can also make a setting to show or not showing questions that had relevance to the 
respondents' answers to the previous questions. If the question did not have to be showed when the respondent answered choices that were not required, then the question will not appear on the smartphone enumerator screen. With this setting, enumerators will work effectively and efficiently when collecting data or interviewing. The enumerator will focus on all questions displayed on the smartphone screen. Therefore, data collection equipment at the research location became more concise in a smartphone.

Data collection with the KoBoCollect application can be done together by more than one enumerator at the same time. In this research, seven smartphones were used for data collection. The experience of field data collection showed that there were no significant problems starting from downloading forms /questionnaires, filling out forms during interviews, and uploading forms that had already filled in the results of interviews. Based on the survey experience conducted, the enumerator's experience in using a smartphone also much determined the smoothness and speed of recording data. Because KoBoCollect provided data recording in various formats, some enumerators who were not accustomed to type on a smartphone will quickly experience problems in recording interview results, specifically the speed in recording data. In addition, the first experience of recording data with a smartphone also affected the enumerator in working in the field. However, this can be managed by conducting training and simulations of using KoBoCollect before conducting research data collection. On the enumerator side, with the use of KoboCollect, the enumerator must have an understanding of the data that recorded in the research. As explained in the introduction, the KoboCollect questionnaire can be arranged systematically, so the decisions regarding data that must be recorded, especially related to quantitative data were performed at the time of data recording. Therefore, enumerators must have a comprehensive understanding of the problem under the research. Another problem that needs to be anticipated was the battery life of the smartphone that being used. Data collection with a smartphone will depend on the battery, so the data collection work must finish when doing an interview, the enumerators' smartphone runs out of battery.

\section{Data collection results}

The results of data collection using KoBoCollect can be presented quickly with a simple analysis, or performed further analysis with tools or software as needed. It really depended on the data recorded in the interview. On the KoBoToollsbox server, the observational data can also be presented in the form of simple mathematical analysis, such as the mean, median, mode and standard deviation of the data, distribution map of the data collection, and some data presentations in graphical form of data that has been uploaded to the server (Figure 4-6). With this instrument, researchers can quickly discovered research data. As in this research, it can quickly be seen that the average age of the respondents was 45.6 years, with a median data age of 45 years, most respondents at the age of 42 years, and the standard deviation of the respondents' age was 10.85. For further analysis, researchers can download tabulated data on the KoBoToolbox website with data formats appropriate to the analysis needed such as XLS, CSV data formats, GPS coordinates (KML), Excel Analyzer, SPSS, and Media Attachment (ZIP). With these choices, it will be easier for researchers to conduct further analysis using other tools. 


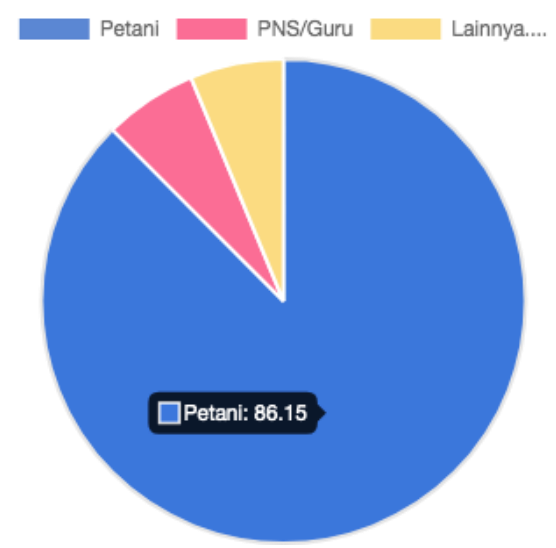

Picture 4. Presentation of respondent's work data in KoBoTollsbox (Research results, 2019)

Picture information:

Petani = farmer

PNS/Guru = government employees $/$ teacher

Lainnya = Others

KoboCollect/Toolbox can also facilitate grouping (quantifying) qualitative data with text answer types. For example, in the questionnaire asked types of bananas that was commonly sold by farmers, with an open question model (text answers). Researchers can still look at quantitative data acquisition such as the percent (\%) of farmers selling kepok bananas or other similar answers. As in this research, there were $21.54 \%$ of respondents who mentioned the type of banana sold before the disease was marmi banana. Marmi banana was the local community name for one type of kepok banana at the research location. Kobo also provided information on each question, how many respondents filled in the data from the total tabulated form. KoBoToolbox will provide a record of the data type, the amount of data filled in and the total questionnaire uploaded to the server. Example notes such as the following quotation "TYPE: "TEXT". 63 out of 65 respondents answered this question. (2 were without data.)" This note showed the type of question items were the texts answered by 63 respondents from 65 completed forms.

The experience of using KoBoCollect in data collection provided an opportunity for researchers to quickly discovered the results of data collection such as the type of banana that was affected, the name of the banana that was best known by farmers, the description of the type of banana that was most affected by blood diseases according to farmers. Picture 5 and 6 showed one of the results of the rapid data presentation by KoBoTollsbox in the graph form of banana plants ownership by farmers. 


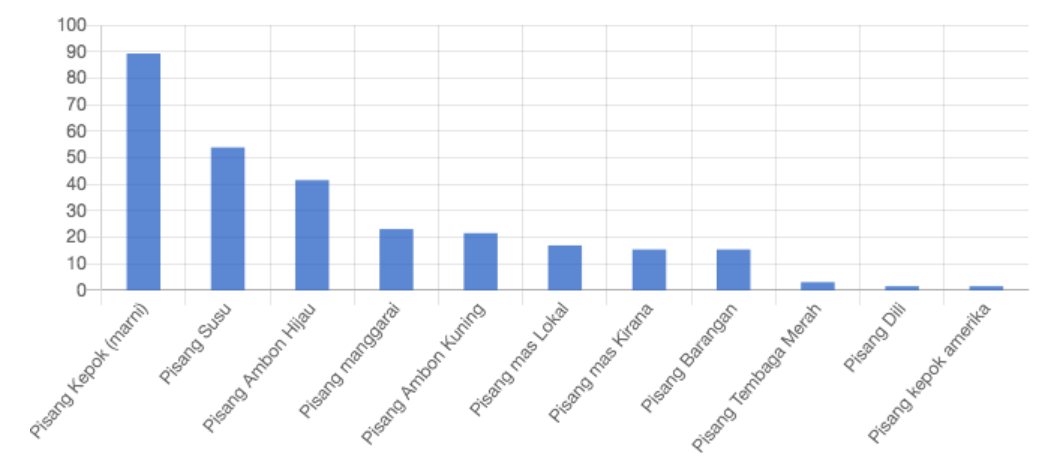

Picture 5. Quick data presentation in the form of bar graphs on the KoBoToolbox server (Research Results, 2019)

Picture information:

Type of bananas; Kepok (marni) banana, milk banana, green ambon banana, manggarai banana, yellow ambon banana, local mas banana, mas kirana banana, barangan banana, tembaga merah banana, dili banana, kepok amerika banana

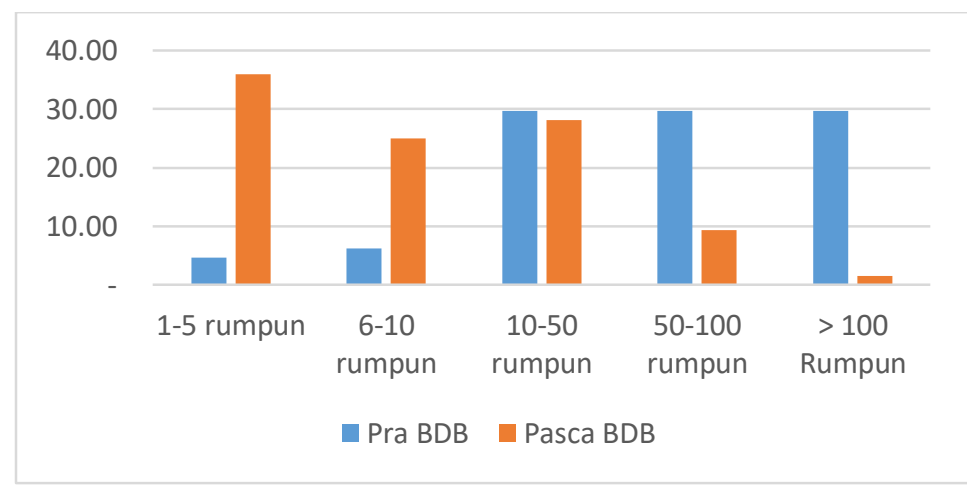

Picture 6. Banana Cluster Ownership by Farmers Before and After BDB

(Research Results, 2019)

Picture information:

Rumpun = cluster

Pra $\mathrm{BDB} \quad=$ pre blood desease

Pasca BDP $=$ post blood desease

In field data collection, often forms or questionnaires that had been prepared carefully before conducting research must be adapted to field conditions. When using conventional instruments, changes were very difficult to do, especially fundamental changes. It's because will related to reprint copy and other obstacles. However, with KoBoCollect, forms changes to adjust field conditions can be done quickly even when conducting research in remote locations. Experience in this research, one of the questions missed at the beginning of the preparation of the questionnaire was the name of the enumerator. In fact, the data was important for researchers related to the performance of the enumerator, and related to the calculation of the payment of collection fees for each enumerator. With KoBoCollect, you can immediately change it as needed. Likewise, the possibility of adding and subtracting questions that must be collected was very possible during in the field.

\section{Discussion}

The use of digital questionnaire instruments greatly assisted researchers in conducting data collection, data tabulation, analysis, and also maintaining data 
accuracy. Digital questionnaires such as monkey survey, typeform, google forms, zoho survey, and gizmo survey developed with various advantages of each. Digital questionnaire was developed to make the survey more effective and efficient (Ismail $\&$ AlBahri, 2019). The use of digital instruments was also very much needed in the field data collection by interviewing method which was guided by a list of questions. KoboCollect as an android-based digital data collection instrument provided convenience, especially in data collection that involving enumerators. Daunhauer et al. (2019) can effectively and efficiently used KoBoCollect to solve the problem of data retrieval in the work location performed by involving volunteers in three places which were in Bucatan, Camanga, and Napuagan. In the engineering field, Narayan et al. (2017) used an instrument similar to KoBoCollect, the open data kit (ODK). ODK was used for collecting, storing and processing various types of data from rain catchment location data, dam, canal and rice field data in the West Timor Island, Sumba and Flores. The used of ODK allowed modification of forms even when researching in remote locations. Allowed parallel data retrieval, and with ODK the work processed will minimize the need to print forms and data, and allowed flexibility, especially in multidisciplinary research. In line with what was delivered by Narayan et al., This research also had the ease in collecting, storing, and managing research data. The same thing was also conveyed by Hartung. et al. (2010) who used ODK to assist work in collecting data for development. Meanwhile, efforts to develop the use of smartphones in data retrieval continued to be performed, as done by Brunette et al. (2012).

Seen from the ease of use, compared to the printed questionnaire, KoBoCollect was relatively easy to use. By the content/subject in KoboCollect was the same as printed questionnaire. KoBoCollect made it easy because the questions that appeared on the screen were only one question, so the interviewer can focus on those questions. In addition, questions that were social or that depended on the choice of previous answers will not be showed if the answer as a requirement was not chosen. This certainly facilitated the implementation of data collection in the field because the enumerator will be more controlled, and not miss any questions, and not be interrupted by questions that should not be asked. This made the implementation of research more effective and efficient. As stated by Handayani et al. (2017) that the use of digital questionnaire instruments led to the implementation of more effective and efficient data collection. The same thing also expressed by Tayal et al. (2015) with the help of ODK, data collection can be done quickly and a smaller error rate. Referring to some of the conveniences that offered, the use of smartphones with the KoBoCollect application can be an option for research data collection instruments.

\section{CONCLUSIONS}

Data collection with smartphones supported by the KoBoCollect application contributed to conducting research more effectively and efficiently. KoBoCollect/toolbox provided easy data collection, save, management and presentation, and fast data tabulation. In addition, the forms in the KoBoCollect/toolbox can be modified immediately during data collection to adjust field conditions even in remote locations. Researchers can immediately discover the resulted data, as in this research it was immediately known that $81.54 \%$ of farmers 
said that blood disease had an impact on the decrease in the population of cultivated banana plants.

\section{RECOMMENDATION}

Based on the conclusions above, the researchers proposed suggestions to other researchers, especially those who will conduct research by collecting field data, especially on a wide range of locations and using volunteers, can consider KoBoCollect/toolbox as an instrument of data collection. KoBoCollect was good to be developed for data collection with participatory volunteer models, as well as reducing the use of paper so that research was more environmentally friendly.

\section{REFERENCES}

Brunette, W., Sodt, R., Chaudhri, R., Goel, M., Falcone, M., Van Orden, J., \& Borriello, G. (2012). Open data kit sensors: A sensor integration framework for android at the application-level. Proceedings of the 10th International Conference on Mobile Systems, Applications, and Services, 351-364. https: / / doi.org/10.1145/2307636.2307669

Dauenhauer, P., Shields, M., McLean Sloughter, J., Stewart, A. J., Lacrampe, C., Magness, E., Ochavillo, J., Limfueco, J., \& Mendoza, A. (2019). Improving shoestring surveys for off-grid humanitarian power projects: Kilowatts for humanity and KoboCollect. In 2018 IEEE Global Humanitarian Technology Conference (GHTC) (pp. 1-6). IEEE. https: / / doi.org/10.1109/GHTC.2018.8601657

Deniau, C., Gaillard, T., Mbagogo, A., Réounodji, F., \& Le Bel, S. (2017). Using the KoBoCollect tool to analyze the socio-economic and socio-cultural aspects of commercial hunting and consumption of migratory waterbirds in the Lakes Chad and Fitri (Chad) [Conference_item]. Conference Proceedings of 2017 EFITA WCCA Congress: European Conference Dedicated to the Future Use of ICT in the Agri-Food Sector, Bioresource and Biomass Sector. https: / / agritrop.cirad.fr/585572/

Handayani, I., Mutmainah, S., \& Rosmawati, O. (2017). Penerapan Rinfo Form Sebagai Media Pengumpulan Data Hasil Kinerja Dosen iLearning. Technomedia Journal, 2(1), 49-68. https://doi.org/10.33050/tmj.v2i1.315

Hartung, C., Lerer, A., Anokwa, Y., Tseng, C., Brunette, W., \& Borriello, G. (2010). Open data kit: Tools to build information services for developing regions. Proceedings of the 4th ACM/IEEE International Conference on Information and Communication Technologies and Development, 1-12. https: / / doi.org/10.1145/2369220.2369236

Ismail, I., \& AlBahri, F. P. (2019). Perancangan E-Kuisioner menggunakan CodeIgniter dan React-Js sebagai Tools Pendukung Penelitian. J-SAKTI (Jurnal Sains Komputer Dan Informatika), 3(2), 337-347. https://doi.org/10.30645/jsakti.v3i2.152

Le Bel, S., Chavernac, D., \& Stansfield, F. (2016). Promoting a Mobile Data Collection System to Improve HWC Incident Recording: A Simple and Handy Solution for 
Controlling Problem Animals in Southern Africa. In F. M. Angelici (Ed.), Problematic Wildlife: A Cross-Disciplinary Approach (pp. 395-411). Springer International Publishing. https://doi.org/10.1007/978-3-319-22246-2_19

Mairawita, Habazar, T., Hasyim, A., \& Nasir, N. (2012). Potensi Trigona SPP. Sebagai Agen Penyebar Bakteri Ralstonia Solanacearum Phylitipe IV Penyebab Penyakit Darah Pada Pisang. J. HPT Tropika, 12(1), 92-101.

Narayan, M., Evans, K., Lamsal, B., Thapa, R., Hobgen, S. E., Myers, B., Wurm, P., Godwin, P. B., Kaho, N. R., \& Markus, J. (2017). Deployment of Open Data Kit for Information Management for Various Engineering Projects In Rural, Indonesia. International Research Journal of Electronics and Computer Engineering, 3(1), 1-6. https://doi.org/10.24178/irjece.2017.3.1.01

Prasetyo, B., \& Trisyanti, U. (2018). Revolusi Industri 4.0 dan Tantangan Perubahan Sosial. IPTEK Journal of Proceedings Series, O(5), 22-27-27. https: / doi.org/10.12962/j23546026.y2018i5.4417

Riwu Kaho, N. P. L. B. (2019). Modul Penggunaan Platform KoBoToolbox/Collect Untuk Pemetaan Anak Stunting dan Ibu hamil di Provinsi Nusa Tenggara Timur [Tidak Dipublikasikan]. Fakultas pertanian Universitas Nusa Cendana.

Tayal, R., Saluja, S., Bedwal, T., \& Sardana, A. (2015). Open data kit-use of smartphone technology for surveying. 2015 International Conference on Advances in Computer Engineering and Applications, 461-464. https://doi.org/10.1109/ICACEA.2015.7164749 